\title{
Stepwise participation of HGF/MET signaling in the development of migratory muscle precursors during vertebrate evolution
}

\author{
Noritaka Adachi ${ }^{1,4^{*}}$ (D) Juan Pascual-Anaya ${ }^{2}$, Tamami Hirai ${ }^{1,2}$, Shinnosuke Higuchi ${ }^{1,2,3}$, Shunya Kuroda ${ }^{1,2,3}$ \\ and Shigeru Kuratani $i^{1,2}$
}

\begin{abstract}
Background: The skeletal musculature of gnathostomes, which is derived from embryonic somites, consists of epaxial and hypaxial portions. Some hypaxial muscles, such as tongue and limb muscles, undergo de-epithelialization and migration during development. Delamination and migration of these myoblasts, or migratory muscle precursors (MMPs), is generally thought to be regulated by hepatocyte growth factor (HGF) and receptor tyrosine kinase (MET) signaling. However, the prevalence of this mechanism and the expression patterns of the genes involved in MMP development across different vertebrate species remain elusive.
\end{abstract}

Results: We performed a comparative analysis of $\mathrm{Hgf}$ and Met gene expression in several vertebrates, including mouse, chicken, dogfish (Scyliorhinus torazame), and lamprey (Lethenteron camtschaticum). While both Hgf and Met were expressed during development in the mouse tongue muscle, and in limb muscle formation in the mouse and chicken, we found no clear evidence for the involvement of HGF/MET signaling in MMP development in shark or lamprey embryos.

Conclusions: Our results indicate that the expressions and functions of both Hgf and Met genes do not represent shared features of vertebrate MMPs, suggesting a stepwise participation of HGF/MET signaling in MMP development during vertebrate evolution.

Keywords: Hepatocyte growth factor HGF, Receptor tyrosine kinase MET, Hypobranchial muscles, Limb/fin muscles, Migratory muscle precursor cells, Vertebrate evolution

\section{Background}

The vertebrate skeletal musculature can be divided into two major categories: cranial muscles derived from head mesoderm, and trunk muscles that originate from somites. In gnathostomes, the trunk muscles are further divided into two groups: epaxial muscles, innervated by the dorsal ramus of the spinal nerve and located dorsal to the horizontal myoseptum, and hypaxial muscles, which are

\footnotetext{
* Correspondence: adaraptor@gmail.com

'Laboratory for Evolutionary Morphology, RIKEN Center for Biosystems Dynamics Research (BDR), 2-2-3 Minatojima-minami, Chuo-ku, Kobe 650-0047, Japan

${ }^{4}$ Present address: Aix-Marseille Université, CNRS, IBDM UMR 7288, 13288

Marseille, France

Full list of author information is available at the end of the article
}

innervated by the ventral ramus of the spinal nerve and situated ventral to the myoseptum [1-4].

The epaxial muscles include muscles of the back associated with vertebrae and the occipital bone, while the hypaxial muscles comprise the subvertebral muscles, body wall muscles, hypobranchial muscles (HBMs, including the tongue muscles), and limb and fin muscles [2]. Of these hypaxial muscles, the tongue and limb muscles have attracted attention due to their unique mode of development, in which their precursors delaminate from the epithelial dermomyotome and travel long distances from their site of origin before muscle formation [5-13]. Intriguingly, the derivatives of these migratory muscle precursors (MMPs) have exhibited great morphological diversity

(C) The Author(s). 2018 Open Access This article is distributed under the terms of the Creative Commons Attribution 4.0 International License (http://creativecommons.org/licenses/by/4.0/), which permits unrestricted use, distribution, and 
in vertebrate history, serving as a key muscular group in helping to understand the evolution of the skeletal muscle system $[2,14-16]$.

Previous studies have identified a number of genes involved in regulating somitic myogenesis, including several key genes involved in MMP development [17-30]. Of these, hepatocyte growth factor ( $\mathrm{Hgf}$; also known as scatter factor) and receptor tyrosine kinase Met (also known as hepatocyte growth factor receptor, c-Met or c-met proto-oncogene) have been shown to play important roles in MMP development. Mice with mutations in these genes show severe defects in MMP derivatives, including muscles of the tongue, diaphragm and limbs, in addition to liver and placental abnormalities [17, 31-37].

Detailed analyses of embryos have suggested two major functions of HGF/MET signaling during MMP development. The first is in facilitating the delamination of the ventral dermomyotome, an initial step in MMP formation. This is supported by observations that Met is expressed in the ventral dermomyotome at the limb level, $H g f$ is expressed in the adjacent limb bud mesenchyme, and cells in the ventral dermomyotome do not show de-epithelialization in $\mathrm{Hgf}$ or Met mutant mice [17, 33, 38-41]. Implant experiments using HGF-soaked beads in chicken and zebrafish further demonstrated its role in dermomyotomal delamination [10, 42-45]. The second role of HGF/MET signaling is exerted during the migration of MMP cells. This is supported by the abnormal development of MMP derivatives in mutant mice, and the expression of Met in migrating limb myoblasts and $H g f$ along the migration route and at the target site, as well as the induction of myoblast translocation by the ectopic application of HGF in the limb bud [17, 33, 36, 40, 46-49].

Based on analyses of expression and function of $\mathrm{Hgf}$ and Met genes in mouse, chicken and zebrafish, the regulation of MMP development by the HGF/MET signaling pathway is assumed to be a shared feature in vertebrates $[16,17,33,45,50]$. However, most of these studies have focused on the expression and function of $\mathrm{Hgf}$ and Met during forelimb muscle (FLM) development, and even an expression profile of both genes is lacking in other MMP derivatives. Furthermore, analysis of $H g f$ and $M e t$ expression has been performed exclusively in Osteichthyan species (bony fishes), such as mouse and zebrafish, but not in chondrichthyes or cyclostomes (cartilaginous fishes and jawless fishes, respectively), representing two other major groups of vertebrates. If Met and Hgf expressions are commonly detected in the migratory myoblasts and their surrounding tissues, respectively, during the delamination and migration processes of muscles other than limbs, HGF/MET signaling would be generally linked to MMP development. In addition, if a similar expression pattern is observed for $\mathrm{Hgf}$ and Met in the MMPs of different vertebrate taxa, HGF/MET signaling would appear to be a shared mechanism for vertebrate MMP development. To test these possibilities, we investigated $H g f$ and Met expressions in mouse, chicken, shark and lamprey embryos, representing all major groups of vertebrates, by focusing on the development of HBMs, together with limb/fin muscles.

\section{Methods}

\section{Sample collection}

Mouse (Mus musculus, C57BL/6 strain), chicken (Gallus gallus), shark (Scyliorhinus torazame), and Arctic lamprey (Lethenteron camtschaticum) embryos were obtained as described in Adachi et al. [51], and staged according to Theiler [52], Hamburger and Hamilton [53], Ballard et al. [54], and Tahara [55], respectively.

\section{Molecular cloning and phylogenetic analysis}

$H g f$ and Met genes of the shark and the lamprey were isolated by the method described in Adachi et al. [56] and [51]. The accession numbers and primer sequences used in the present study are listed in the Additional file 1: Table S1. Phylogenetic analysis of HGF and MET was performed as described in Adachi et al. [51]. Briefly, the amino acid sequences of orthologous genes in other vertebrates have been assembled from GenBank (http:// www.ncbi.nlm.nih.gov/) and Ensembl (http://www.ensembl. org/index.html), and then aligned with MAFFT [57] (http://www.ebi.ac.uk/Tools/msa/mafft/). Gaps in the multiple sequence alignments were removed by trimAl version 1.2 [58] and formatted into NEXUS format by readAl v.1.2 (bundled with the trimAl package). Bayesian inference with MrBayes 3.2.6 was performed under the assumption of an LG + I + G evolutionary model [59].

\section{In situ hybridization}

Whole-mount in situ hybridization was performed following the method described in Adachi et al. [60]. Five different probes and a slightly modified method of Adachi et al. [56] with 5\% dextran sulfate in the hybridization solution, were also used for in situ hybridization of shark Met gene. Sections were prepared after whole-mount in situ hybridization as described in Adachi et al. [51]. Images of whole embryos were photographed with a Leica MZ16FA (Leica Camera AG, Wetzlar, Germany), and images of sections were taken with an Olympus BX53 light microscope (Olympus, Tokyo, Japan).

\section{Results}

Hgf and Met expression during development of the HBM and FLM in mouse embryos

We first observed the expression patterns of $\mathrm{Hgf}$ and $\mathrm{Met}$ genes in mouse embryos, in which the involvement of HGF/MET signaling in both delamination and migration of 
myoblasts has been demonstrated [11, 13, 17, 33, 34, 36]. Because previous studies have shown that $H g f$ is expressed in the limb bud mesenchyme and Met is expressed in the ventral part of dermomyotome at the limb level before the delamination and in the migrating limb myoblasts, we mainly assessed the development of HBMs from embryonic day $(E)$ 10, when the muscles initiate delamination from anterior somites [17, 38-41, 46, 48, 61].

$H g f$ transcripts were detected in the pharyngeal arches, the liver anlage, the dorsal and ventral portion of forelimb bud, and along the migration route of HBM precursors (tHBM) at E10, and a similar expression pattern was observed at E10.25, when HBM precursors circumvented the pharyngeal arches posteriorly (Fig. 1a-f) [33, 51]. In transverse sections after in situ hybridization, $H g f$ expression was detected in the central part of the hyoid arch and in the peripheral mesenchyme of pharyngeal arches (Fig. 1c, d). We also confirmed that $H g f$ was expressed in the mesenchyme lateral to the common cardinal vein, the dorsal part of the pericardium, and the medial part of the hyoid arch, in the region that HBM precursors pass through to reach the ventral pharynx (Fig. 1c-e) [51]. In addition, $H g f$ expression was detected in limb bud mesenchyme close to the ventrolateral lip of the dermomyotome (Fig. 1f).

At E10, Met mRNA was expressed weakly in pharyngeal endoderm and the liver anlage. Expression was also detected in the ventral part of the dermomyotome at the neck and limb bud levels and in FLM precursors in the limb bud (Fig. 1g). In E10.25 embryos, additional Met signals were detected in the dorsal parts of dermomyotome and HBM precursors (Fig. 1h). In transverse sections, we found Met-positive HBM precursor cells in the mesenchyme lateral to the common cardinal vein and the pericardial mesoderm, where $H g f$ expression was also detected (Fig. 1c-e, 1i-k). Met was also expressed in the ventrolateral lip of the dermomyotome and in delaminated FLM precursors in the limb bud (Fig. 11).

Thus, our observations in mouse embryos revealed that Met is expressed in the ventral dermomyotome at the neck and forelimb levels and in the migrating HBM and FLM precursors, while $H g f$ is expressed in the mesenchyme near the ventral dermomyotome and along the migration route of HBM and FLM precursor cells.

Hgf and Met expression and development of chick MMPs We next examined $H g f$ and Met expressions in chick embryos, as no detailed analysis of Met gene expression during muscle development has been reported to date, and the spatiotemporal expression pattern of Met has not been compared thoroughly with that of $\mathrm{Hgf}$ in this model species [43, 47, 62, 63].

At Hamburger and Hamilton stage 17 (HH17), when HBM precursors initiate delamination from the anterior somites, chicken $H g f$ was expressed in parts of the optic cup and in the mesoderm of the pharyngeal arches (Fig. 2a) $[62,64]$. However, unlike in the mouse, $H g f$ transcripts were not detected along the trajectory of HBM precursors in chicken as reported previously (Fig. 2a) [64]. Hgf expression was observed uniformly in the limb buds and did not clearly exhibit dorsoventrally separated domains at stages HH17, HH18 or HH20 (Fig. 2a-c) [43, 47, 62]. Hgf expression was also found in the tissue lateral to the lateral plate mesoderm (Fig. 2a, b).

Chicken Met expression was detected in the otic vesicle, the dorsal and ventral portions of the dermomyotome, and the lateral tissue of the lateral plate mesoderm at stage HH17 embryos (Fig. 2d). At stage HH18, weak Met expression was observed in the precursor cells of the HBM and FLM (Fig. 2e). Chicken Met expression was sustained in HBM and FLM precursors at stage 20, and further detected in the ventral pharyngeal arches, cucullaris muscle progenitors, the anterior and posterior edges of the dermomyotome and in the ventral surfaces of limb buds (Fig. 2f) [65].

Thus, we found Met expressions in the ventral dermomyotome at the neck level and in HBM precursors, without obvious $H g f$ expressions in the neighboring tissues. This is in contrast to the situation in the mouse embryos where $H g f$ expression was also seen along the migration route of HBMs.

\section{Hgf and Met expression in shark embryos}

The differential expression patterns of $H g f$ and $M e t$ between mouse and chicken embryos suggested further phylogenetic diversity of the patterns in these genes. To clarify the evolution of the HGF/MET signaling in MMPs, we performed a wider phylogenetic sampling of vertebrate taxa. Accordingly, we cloned S. torazame $\mathrm{Hgf}$ and Met genes, and performed in situ hybridization in developing shark embryos (Fig. 3 and Additional file 1 Figure S1-S3).

At stage 25, when HBM precursors start to extend ventrally from the anterior somites [51, 54], shark $H g f$ mRNA was detected in the periocular mesenchyme, pharyngeal arches and in the mesenchyme adjacent to the common cardinal vein (Fig. 3a). We also observed expression in the cloacal anlage and the possible caudal vein in the tail region, but $H g f$ transcripts were not observed in the pectoral or pelvic fin buds (Fig. 3a, b). At stage 27, when HBM precursors resided lateral to the pericardium and fin muscle precursors expanded into the fin bud mesenchyme [51], we found an Hgf expression pattern similar to that in stage 25 with additional $H g f$ signals in postotic pharyngeal arches and the posterior region of the pectoral fin buds (Fig. 3c-h). In histological sections, we confirmed $H g f$ expression in the ectomesenchyme of pharyngeal arches and the lateral mesenchyme of anterior and common cardinal veins (Fig. 3f-h). However, the pericardium, the anterior parts 


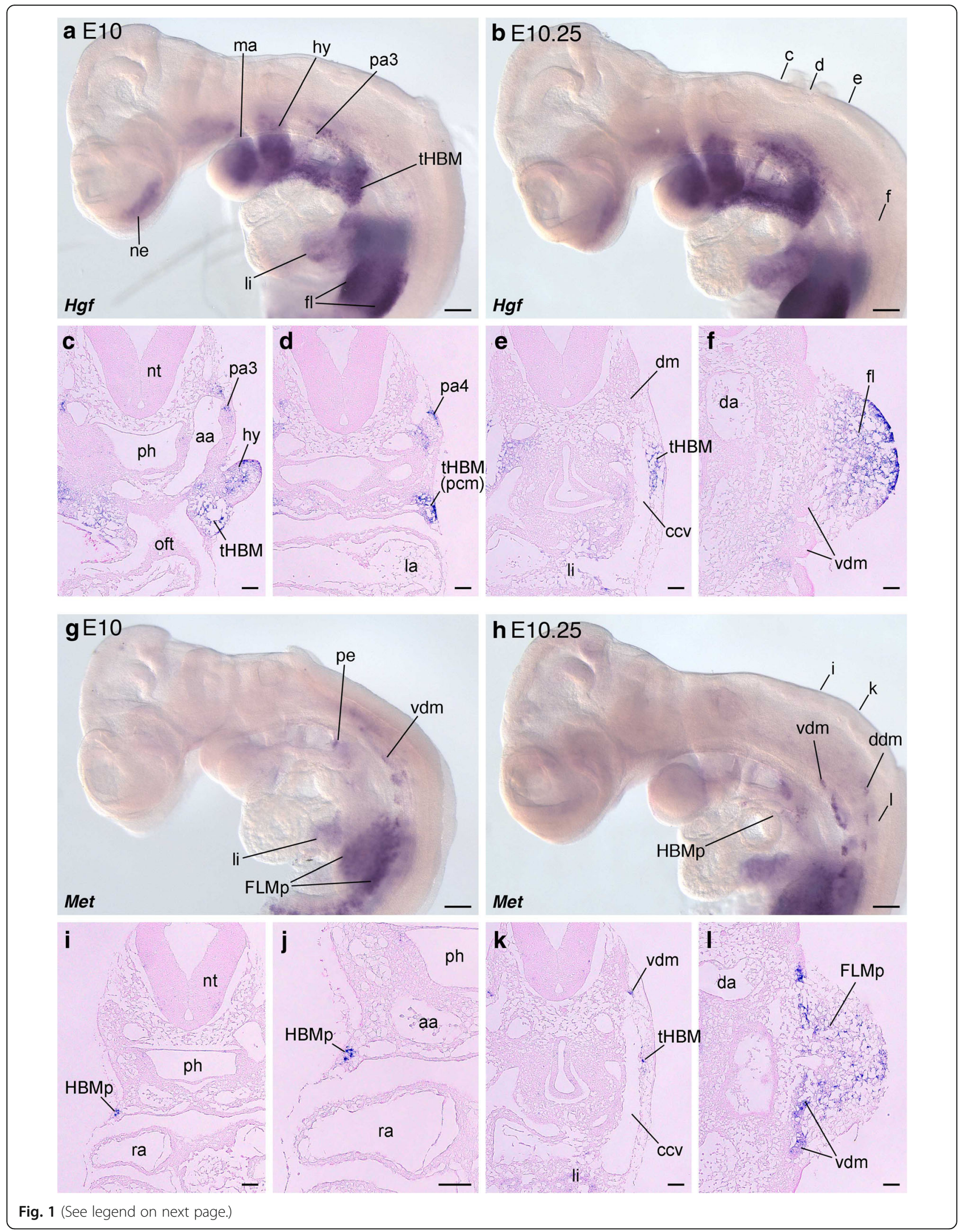


(See figure on previous page.)

Fig. $1 \mathrm{Hgf}$ and Met expressions in mouse embryos. $\operatorname{Hgf}(\mathbf{a}, \mathbf{b})$ and $\operatorname{Met}(\mathbf{g}, \mathbf{h})$ expression pattern in mouse embryos at E10 (a, c) and E10.25 (b, d) stages. Lateral views. Transverse sections of E10.25 embryos after in situ hybridization with $\mathrm{Hgf}(\mathbf{c}-\mathbf{f})$ and Met (i-l) probes. The dorsal pericardial region in (i) is magnified in (j). Section levels are indicated in $(\mathbf{b})$ and $(\mathbf{h})$. Note that Hgf is expressed in the migration route of HBM precursors, and also in the dorsal and ventral part of forelimb bud. Met expression was found in HBM and FLM precursors. aa, arch artery; ccV, common cardinal vein; da, dorsal aorta; ddm, dorsal part of dermomyotome; dm, dermomyotome; fl, forelimb bud; FLMp, forelimb muscle precursors; HBMp, hypobranchial muscle precursors; hy, hyoid arch; li, liver anlage; ma, mandibular arch; ne, nasal epithelium; nt, neural tube; oft, outflow tract; pa3, third pharyngeal arch; pa4, fourth pharyngeal arch; pe, pharyngeal endoderm; ph, pharynx; ra, right atrium; tHBM, trajectory of hypobranchial muscle; vdm, ventral part of dermomyotome. Scale bars on whole embryos, $200 \mu \mathrm{m}$. Scale bars on sections, $50 \mu \mathrm{m}$

of pectoral fin buds and the pelvic fin buds were devoid of $H g f$ expression. A similar expression pattern was also observed at stage 28 (Additional file 1: Figure S3a), and we also found further expression domains of $\mathrm{Hgf}$ in the posterior part of the pelvic and dorsal fin buds (Additional file 1: Figure S3b, c).

Compared with $\mathrm{Hgf}$, it was much more difficult to detect clear signals of Met in shark embryos, although we tried five distinct probes and two different protocols. A very faint, but relatively consistent expression pattern was observed in our in situ hybridization analyses with shark Met probe 1. We also performed in situ hybridization with the sense riboprobe of shark Met probe 1 (Fig. 3 and Additional file 1: Figure S3j, k). At stage 25, Met transcripts were detected in the cranial nerves (IX and X), the pharyngeal endoderm including gill buds and the ventral dermomyotome at the pectoral fin level (Fig. 3i). In the posterior part of the body, transcripts were observed in the ventral dermomyotome at inter-fin and pelvic fin levels, the cloacal anlage and the region of the caudal vein (Fig. 3j). At stage 27, Met expressions in the cranial nerves (V, IX, and $\mathrm{X}$ ), gill buds, the cloaca anlage and the caudal vein were still detectable, but we did not find Met expression in the ventral part of the dermomyotome, nor in ventrally extending muscle precursors in the fin buds (Fig. 3k, l). At stage 28, we found Met expressions in the dorsal and posterior edges of the dermomyotome from postotic to pectoral fin levels, the posterior end of pectoral fin buds and the caudal

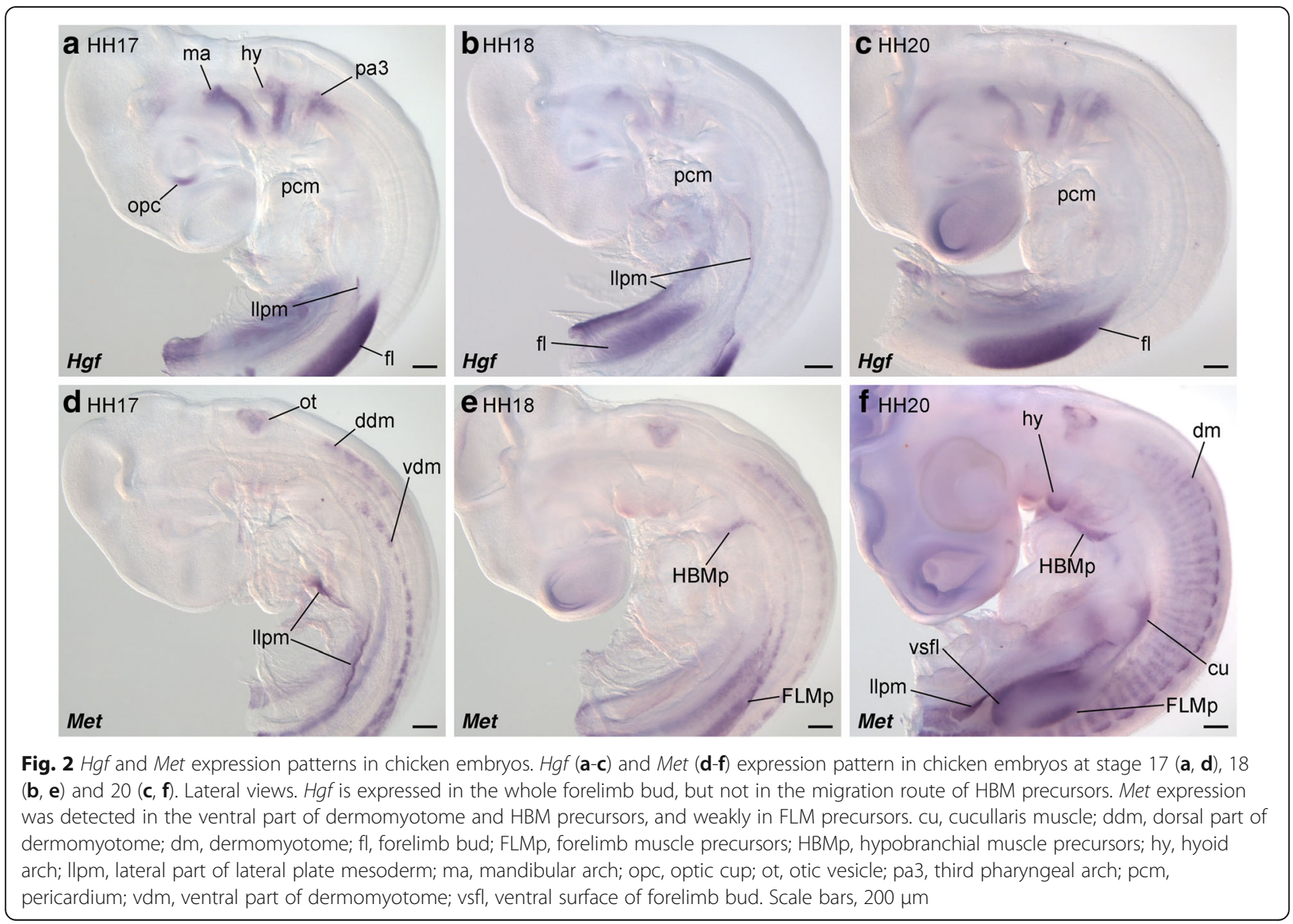




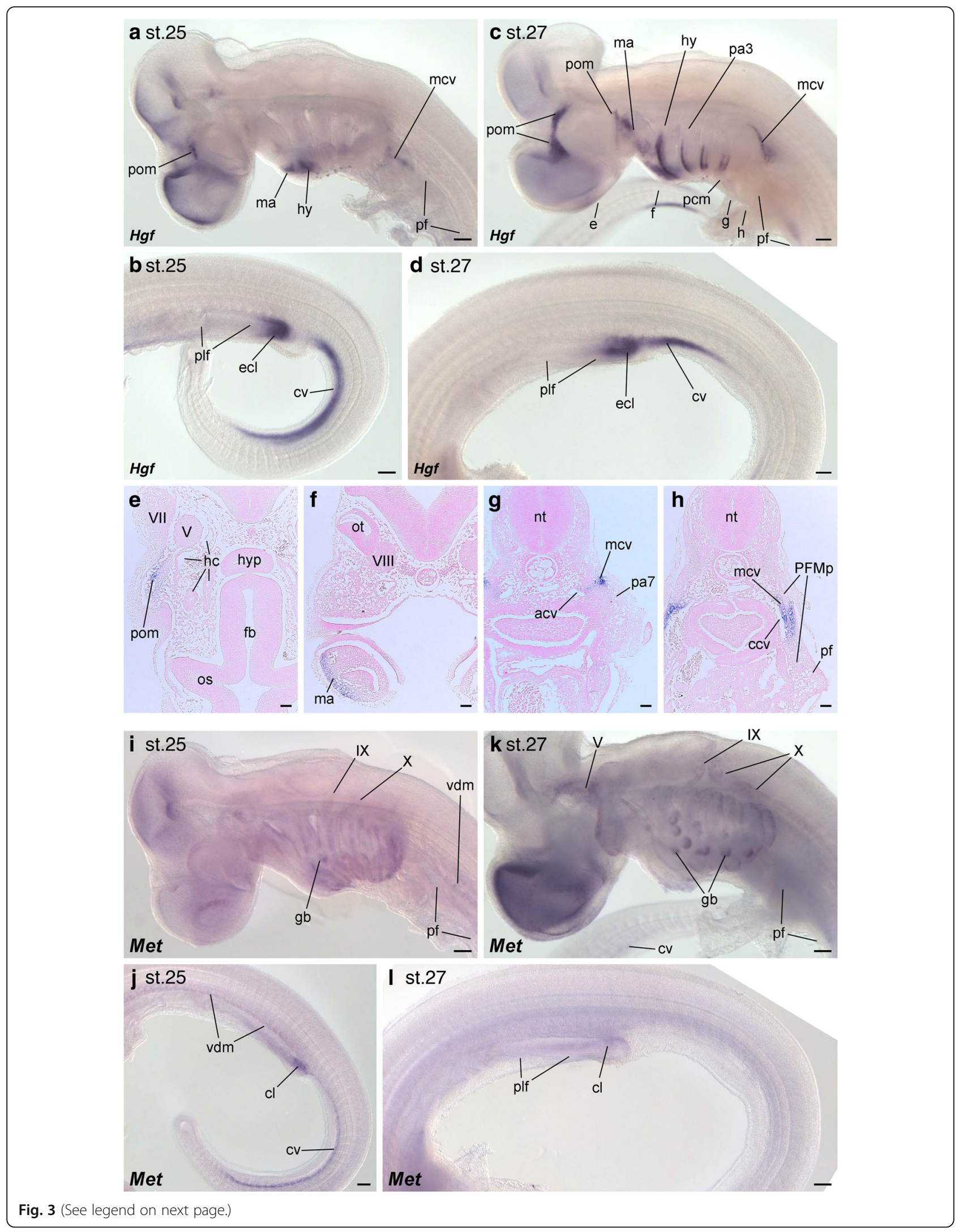




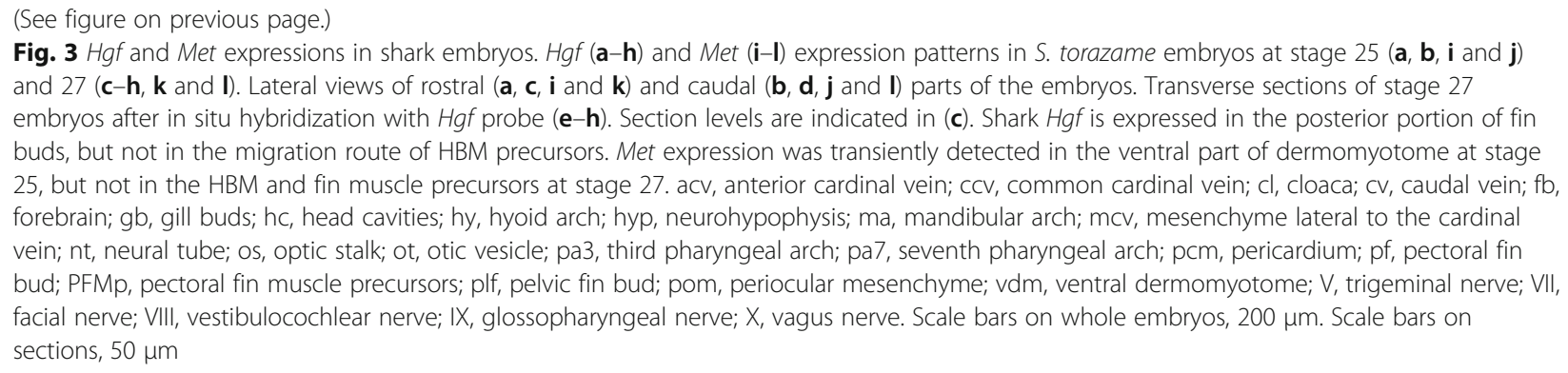

part of intestinal primordium, including the cloacal anlage (Additional file 1: Figure S3d-g). Although in situ hybridization analysis could cause non-specific staining in tubular structures, such as gill buds and cloaca anlage, we constantly observed Met expression in those structures (Fig. 3i-l and Additional file 1: Figure S3d-g) (four of five embryos assayed at stage 25, all six embryos assayed at stage 27 and 11 of 12 embryos assayed at stage 28 ), and did not observe staining in embryos hybridized with Met sense probe (Additional file 1: Figure S3j, k) (two embryos). We occasionally observed Met expression in the dermomyotome regions at trunk and tail levels at stage 28 (four in twelve embryos), but expression was never detected in the muscle precursors of pelvic fins (Additional file 1: Figure S3f).

Overall, we did not detect S. torazame Hgf expression along the migration route of HBM precursors nor in the entire fin bud mesenchyme. In addition, we found no clear Met expression during the ventral extension of HBM and pectoral and pelvic fin muscle precursors in shark embryos.

\section{Hgf and Met expressions and lamprey HBM development}

We did not observe $H g f$ and Met expression, as would be expected if these genes were involved in the delamination and migration of shark MMPs. However, these expression patterns could represent a derived condition of cartilaginous fishes, which exhibit an epithelial nature in various mesodermal tissues $[1,14,66,67]$. To test this possibility, we assessed the expression patterns of $H g f$ and Met cognate genes during HBM development in the Arctic lamprey, which serves as an outgroup of gnathostomes for phylogenetic comparisons.

We screened a lamprey embryonic transcriptome based on RNA-sequencing data [68] and found two Hgf-like and two Met-like genes. Phylogenetic analyses revealed that the two Hgf-like genes were clustered outside the HGF and MST1 groups, so we named these two genes as $H g f / M s t 1 A$ and $H g f / M s t 1 B$, respectively (Additional file 1: Figure S1). On the other hand, each of the two Met-like genes grouped with either MET or MST1R, suggesting-albeit not with strong bootstrap support-that the lamprey has a homolog for each gene (Additional file 1: Figure S2).
We conducted in situ hybridizations of these four genes in stage 26 lamprey embryos, when the ventrolateral part of somites initiate the ventral extension above the pericardium, and at stage 27, when HBM precursors pass through the lateral side of the pericardium and posterior pharyngeal arches [51]. Hgf/Mst1A was expressed in the oral epithelium, the pharyngeal endoderm, pronephros and the liver anlage, and a similar expression pattern was observed in embryos at stage 27 (Fig. 4a, b). Hgf/Mst1B transcripts were detected in the floor of the pharyngeal endoderm and in the liver anlage at stages 26 and 27 (Fig. 4c, d). In addition to these stages, gene expression analyses were also performed in earlier and later stage embryos, yet neither gene was expressed along the trajectory of lamprey HBM (Additional file 1: Figure S4a, b).

Lamprey Met was expressed in the anterior portion of the nasohypophyseal placode, the brain and neural tube, the cranial nerves (IX and X) and the ventral aorta at stage 26. Later on, at stage 27, lamprey Met gained an additional expression domain in the oral epithelium, while it was downregulated in the central nervous system (Fig. 4e, f). In the meanwhile, Mst1r expression was detected in the posterior part of the nasohypophyseal placode, the oral epithelium and the pharyngeal endoderm during the same stages (Fig. 4g, h). However, expressions of Met and Mst1r in somites and HBM precursors were never observed in our analyses. We also investigated gene expression at other embryonic stages, but failed to detect the expression of either gene in the ventral dermomyotome or developing HBM precursors (Additional file 1: Figure S4c, d).

Thus, in contrast to the situation in mammals and birds, the receptor-ligand pair HGF/MET does not appear to be involved in the development of migratory myogenic progenitor cells of the HBM in lampreys.

\section{Discussion}

A paracrine factor, HGF, and its receptor, MET, have been regarded as key signaling components regulating the development of MMPs in vertebrates. However, this idea is mainly based on results from mouse embryos, and a broader phylogenetic analysis has not been performed to date. Here, we investigated the embryonic expression patterns of $\mathrm{Hgf}$ and Met in the shark and lamprey, 
st.26
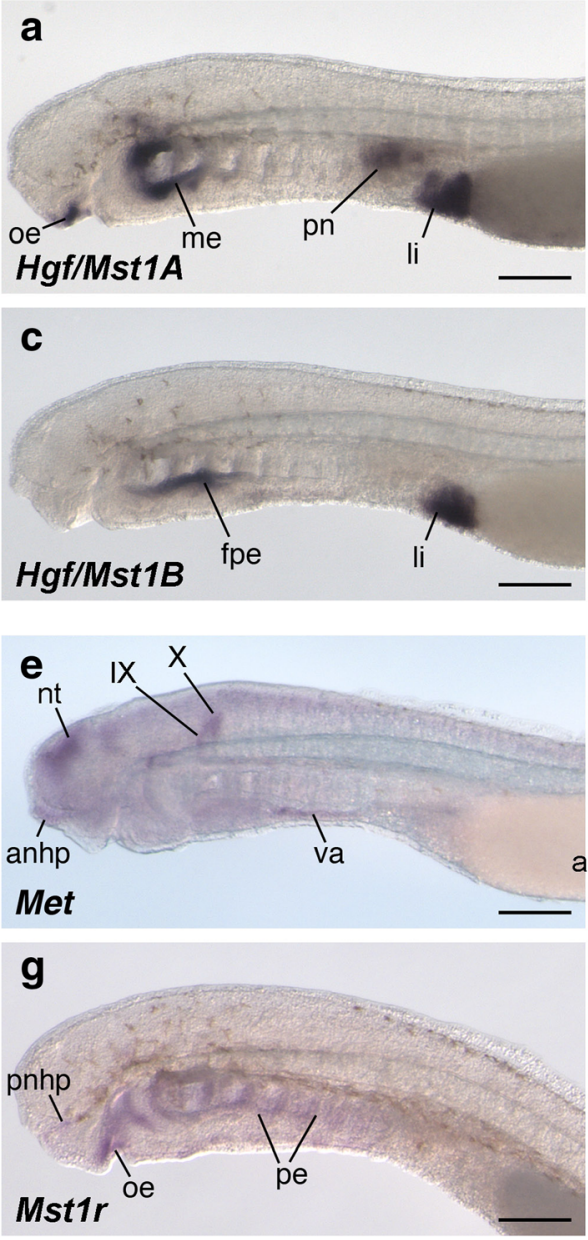

st.27

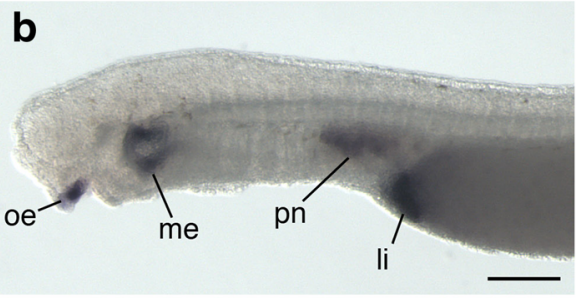

d
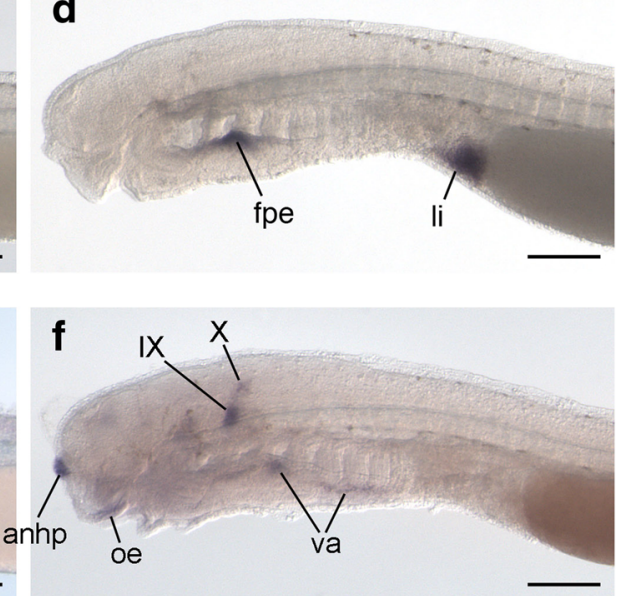

h

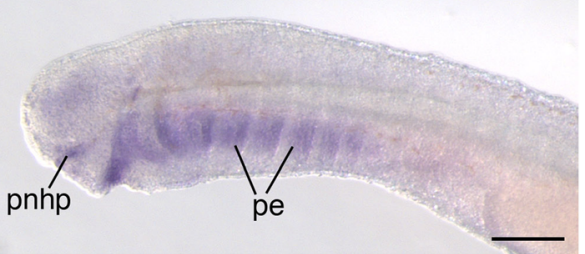

Fig. 4 Expression pattern of Hgf and Met cognate genes in lamprey embryos. Hgf/Mst1A (a, b), Hgf/Mst1B (c, d), Met (e, f), and Mst1r (g, h) expression pattern in lamprey embryos at stage $26(\mathbf{a}, \mathbf{c}, \mathbf{e}$, and $\mathbf{g})$ and $27(\mathbf{b}, \mathbf{d}, \mathbf{f}$, and $\mathbf{h})$. Lateral views. Note that transcripts of Hgf/Mst1A and B genes were not detected in the tissue near the ventral part of dermomyotome, nor in the trajectory of HBM precursors. Met expressions were not observed in somites and HBM precursors. anhp, anterior nasohypophyseal placode; fpe, floor of pharyngeal endoderm; li, liver anlage; me, mandibular arch endoderm; nt, neural tube; oe, oral epithelium; pe, pharyngeal endoderm; pn, pronephros; pnhp, posterior nasohypophyseal placode; va, ventral aorta; IX, glossopharyngeal nerve; X, vagus nerve. Scale bars, $200 \mu \mathrm{m}$

in addition to the mouse and chicken, and revealed that the spatiotemporal expression patterns of $\mathrm{Hgf}$ and $\mathrm{Met}$ were not consistent, but rather diverse among vertebrates during the development of HBMs and paired appendage muscles.

\section{HBM development and HGF/MET signaling}

In mouse and chicken embryos, Met expression is initially observed in the ventral dermomyotome of anterior somites and subsequently in the ventrally extending HBM precursors (Figs. 1 and 2). A similar Met expression has also been found in zebrafish HBMs (sternohyoideus muscle) $[45,69]$, although not all studies reported this muscular expression [50,70,71]. Hgf, on the other hand, is expressed along the migration route of HBM precursors in the mouse (Fig. 1a-f), consistent with the function of HGF/MET signaling in the delamination and migration of the mouse $\mathrm{HBM}$, as demonstrated previously $[17,33,34,36]$. However, a similar spatial expression pattern of $\mathrm{Hgf}$ transcripts is not observed in chicken embryos (Fig. 2) [64], nor has it been reported in zebrafish [45, 70, 71]. In addition, shark and lamprey embryos did not show Hgf expression along the developmental trajectory of HBM, or Met expression in HBM precursors, either (Figs. 3 and 4). These data indicate that the expression patterns of $H g f$ and Met genes in HBM development are discordant among vertebrates, and that the regulation of HBM development by HGF/MET signaling may be an autapomorphic feature of mammals, or even possibly specific to the mouse lineage (Fig. 5).

As already mentioned, Met expression is observed in HBM precursors but $H g f$ transcripts do not accumulate along the migration route of the myogenic precursor cells 


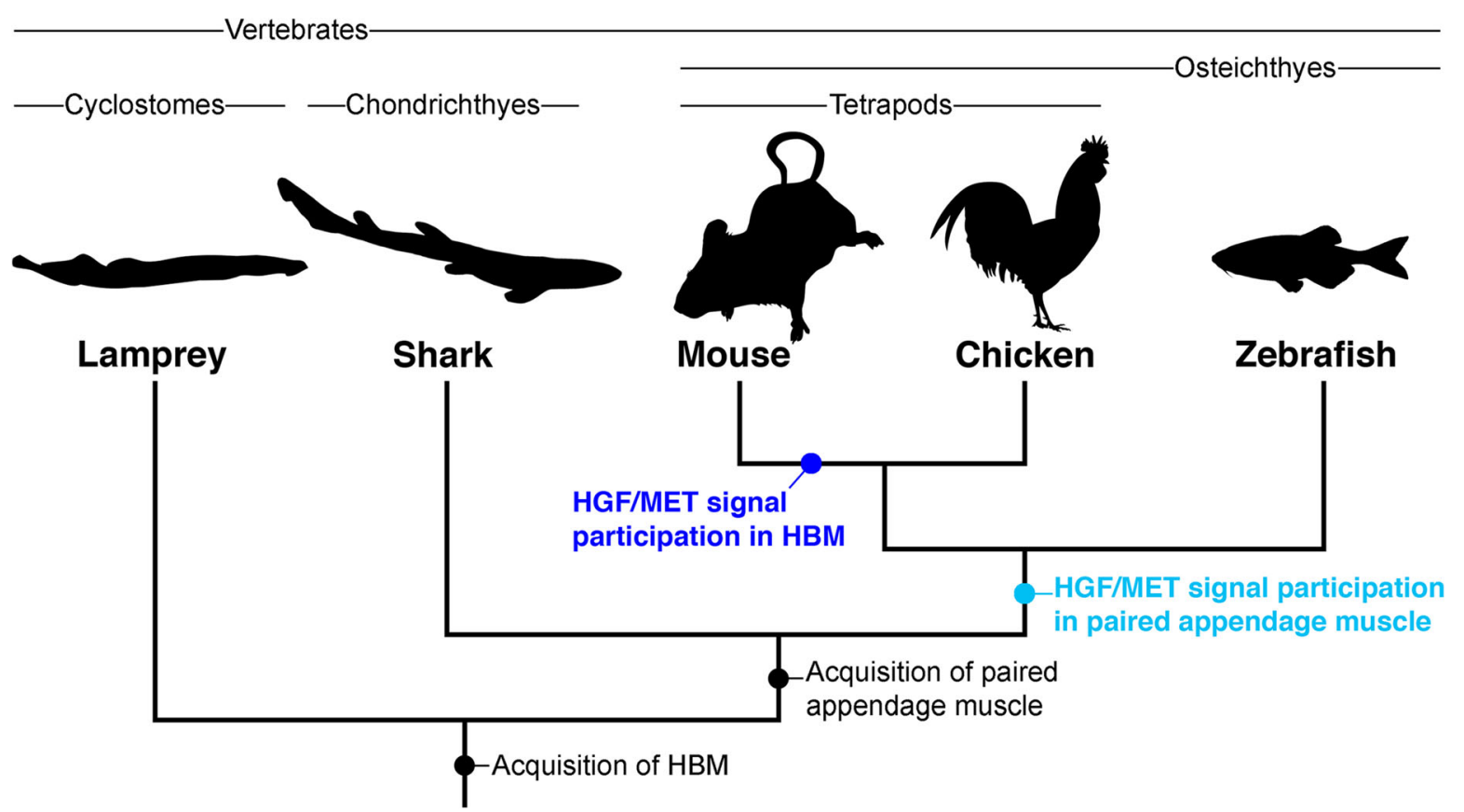

Fig. 5 Stepwise participation of HGF/MET signaling in MMP development. A vertebrate phylogeny and a hypothetical scenario of the participation of HGF/MET signaling in MMPs. A stem osteichthyan acquired Met expressions in MMPs and Hgf expressions in fin buds, and established the delamination (and possibly the migration) of fin MMPs by HGF/MET signaling. A mouse ancestor gained Hgf expressions in the migration route of HBM and evolved HGF/MET signal pathway in HBM development. HBM, hypobranchial muscle

in chicken and zebrafish embryos (Fig. 2) [45, 64, 69-71]. These observations imply an HGF-independent function of MET in HBM development [35, 72]. Alternatively, the expression of Met may be unrelated to the delamination and migration of HBM precursors, and mechanisms distinct from HGF/MET signaling may be involved in MMP development in these species [73]. Notably, our data suggest that other mechanisms must be involved in the migration of shark and lamprey HBMs. Even in the mouse embryo, the expression of Met seems to be detectable only partially in HBM precursors (Fig. 1) (compare with Pax3 expression; [51]). Consistent with this, Met mutant mice show a defect only in a subset of HBMs (the tips of tongue muscles) [17]. These results suggest that additional mechanisms are also involved in HBM formation in the mouse.

\section{Limb/fin muscle development and HGF/MET signaling}

We also found phylogenetically heterogeneous patterns of $\mathrm{Hgf}$ and Met expression in limb/fin muscle development. In mouse embryos, $H g f$ is expressed both in the dorsal and ventral parts of limb buds, while Met was expressed in the ventral dermomyotome and migrating FLM precursors (Fig. 1) [17, 38-41, 46, 48]. On the other hand, in chicken embryos, $H g f$ expression is detected in the whole limb bud mesenchyme at stages HH17-20 (Fig. 2), which has also been reported in earlier developmental stages [63]. At later stages, chick $H g f$ expression becomes restricted to the anterior part, and subsequently to the distal portions of limb buds [43, 47, 49]. Thus, unlike in the mouse, dorsoventrally separated $H g f$ domains are absent in chicken limb buds. As in the early stages of chicken $H g f$ expression patterns, zebrafish $h g f a$ transcripts are observed in the entire fin buds before MMP migration and after the dorsoventral separation of pectoral fin muscle precursors $[45,50,70,71]$.

Despite the considerable differences in $H g f$ distribution in limb/fin buds, however, chicken and zebrafish Met genes are expressed in the ventral dermomyotome and delaminated myoblasts of paired appendages, as observed in mouse embryos (Fig. 2) [45, 50, 69, 71]. In contrast, we were unable to detect Met expression in fin muscle progenitors and $\mathrm{Hgf}$ expression in the whole fin buds in shark embryos (Fig. 3). Together with previous observations, these results suggest that the involvement of HGF/MET signaling in the delamination of limb/fin muscle progenitors is a trait present in the lineage of the Osteichthyes. Two alternative scenarios can be derived from these observations: either the involvement of HGF/MET signaling was an innovation in the lineage of bony fishes, and was not present in the last common ancestor of jawed vertebrates, or it was indeed present in the last common ancestor of gnathostomes, but was secondarily lost in chondrichthyans. Testing which scenario is correct would require studying other chondrichthyan embryos, such as the skate and elephant shark, in future research. However, considering the data at hand-for instance the lack of $H g f$ 
and Met expressions in MMP in the lamprey-we favor the former scenario in which HGF/MET signaling in MMPs of paired appendages was acquired in the lineage of bony fishes (Fig. 5). Last, the dorsoventral deployment of limb muscles by HGF/MET signaling seems to be an apomorphic trait of mammals (Fig. 5), but additional studies in other mammalian taxa will be necessary to characterize this mouse oddity.

The histological structure of fin myoblasts in cartilaginous fishes has long been a source of interest, and now it becomes a matter of debate whether it consists of epithelial progenitor cells specific to the lineage, or mesenchymal cells as in other gnathostomes [1, 14, 74, 75]. Because previous studies revealed the involvement of HGF/ MET signaling in the delamination of the dermomyotome at the limb/fin levels in mouse, chicken and zebrafish embryos, and a recent study reported the de-epithelization of fin myoblasts in shark embryos [33, 42, 43, 45, 75], one would expect to detect $H g f$ and Met gene expression in shark fin buds. However, these genes were not expressed at the right time in the right place to allow them to be involved in the delamination and migration of paired fin myoblasts in shark embryos. Shark $H g f$ mRNA was detectable only in the posterior part of pectoral fin buds after the entrance of pectoral fin muscle precursors in the fin buds. Furthermore, shark Met was not expressed in pectoral and pelvic fin muscle precursors as they entered the fin buds (Figs. 3 and Additional file 1: Figure S3). Although further studies are needed, these data suggest that the early development of shark fin myoblasts is not regulated by HGF/ MET signaling.

\section{Developmental nature of the vertebrate MMP}

Understanding of vertebrate MMP development at the molecular level so far has included the expressions of $P a x 3, L b x 1$ and their related genes, together with the de-epithelialization and migration from the ventral dermomyotome controlled by HGF/MET signaling [12-16, 74-76]. However, in the present study, genetic control of these muscle development has diversified during evolution, while morphologically homologous patterns of the muscles have been largely conserved. This fact would provide an example of developmental system drift, in which developmental infrastructure can evolve without the pattern of phenotypes [77]: the MMP development appears to be independent from $\mathrm{Hgf}$ and $\mathrm{Met}$ expression both in lamprey and shark embryos, whereas both the genes are expressed in the muscular development of paired appendages in Osteichthyes, and finally the genes have become indispensable for the morphogenesis of mouse HBMs (Fig. 5). We thus propose a hypothesis that HGF/MET signaling participated in a stepwise manner in the MMP developmental program along vertebrate phylogeny (Fig. 5). Our study also unveiled MMP formation without $H g f$ and Met expression in the shark and lamprey, implying that the origin of the vertebrate MMP is independent of HGF/MET signaling. Further analyses of other ligands and receptors that are thought to play a role in MMP development and their genetic relationships with $P a x 3$ and $L b x 1$ genes, would provide a better framework for the understanding of skeletal muscle development in vertebrates [13, 49, 78-81].

\section{Conclusions}

Here, we used comparative embryological analyses to show that the expression patterns of $H g f$ and Met in MMP development are highly diverse across vertebrate species. In HBM development, we found both $H g f$ and Met expression only in mouse embryos. $\mathrm{Hgf}$ expression in limb/fin buds and Met expressions in limb/fin myoblasts were exclusively observed in Osteichthyan species. Furthermore, we found no evidence of the involvement of HGF/MET signaling in shark and lamprey MMP development. These observations demonstrate that HGF/MET signaling is not a general regulator of MMPs for all vertebrates, but rather suggest a stepwise participation of HGF/ MET signaling in MMP development during evolution. Our results further suggest that other mechanisms are involved in MMP development, including in mouse HBMs.

\section{Additional file}

Additional file 1: Supplementary Figures and Table. (DOCX 4908 kb)

\begin{abstract}
Acknowledgements
We thank K. Shirato for his help in shark fishing, and E. Momota, K. Yamamoto and S. Shibuya for the maintenance of adult lampreys and sharks. Drs. F. Sugahara, R. Kusakabe, W. Takagi, Y. Kageyama and Y. Nakai helped sampling of lamprey and shark embryos. Drs. H. Nagashima and M. Takechi helped in the sampling of chicken and mouse embryos. We also thank Laboratory for Phyloinformatics, RIKEN BDR, for sharing shark sequence data. Dr. R. Kusakabe kindly provided comments on the manuscript. We are especially grateful to Drs. F. Sugahara and R. G. Kelly for helpful discussions and critical reading of the manuscript.
\end{abstract}

\section{Funding}

This work was supported in part by Grant-in-Aid for Scientific Research (A) 15H02416, Grant-in-Aid for Scientific Research on Innovative Areas 17H06385 and a Naito Grant for the Promotion of Focused Research (The Naito Foundation) to S.Kuratani, and by Yamada Science Foundation and Bourses du Gouvernement Français to N.A.

\section{Availability of data and materials}

All sequences generated in this study are publicly available in NCBI GenBank under the accession numbers LC360981-LC360986.

\section{Authors' contributions}

NA and SKuratani designed the research. NA, JP-A, TH, SH and SKuroda performed analyses. NA, JP-A and SKuratani wrote the manuscript. All authors read and approved the manuscript.

\section{Ethics approval}

All animal experiments were carried out with the approval of the Institutional Animal Care and Use Committee of RIKEN, Kobe Branch. 


\section{Competing interests}

The authors declare that they have no competing interests.

\section{Publisher's Note}

Springer Nature remains neutral with regard to jurisdictional claims in published maps and institutional affiliations.

\section{Author details}

'Laboratory for Evolutionary Morphology, RIKEN Center for Biosystems Dynamics Research (BDR), 2-2-3 Minatojima-minami, Chuo-ku, Kobe 650-0047, Japan. ²aboratory for Evolutionary Morphology, RIKEN Cluster for Pioneering Research, 2-2-3 Minatojima-minami, Chuo-ku, Kobe 650-0047, Japan. ${ }^{3}$ Department of Biology, Graduate School of Science, Kobe University, Kobe 657-8501, Japan. ${ }^{4}$ Present address: Aix-Marseille Université, CNRS, IBDM UMR 7288, 13288 Marseille, France.

\section{Received: 30 March 2018 Accepted: 11 May 2018}

Published online: 18 June 2018

\section{References}

1. Goodrich E. Studies on the Structure and Development of Vertebrates. Macmillan, London: MacMillan and Co., Limited. London; 1930.

2. Romer AS, Parsons TS. The vertebrate body. Saunders Coll. Philadelphia; 1977.

3. Spörle R. Epaxial-adaxial-hypaxial regionalisation of the vertebrate somite: evidence for a somitic organiser and a mirror-image duplication. Dev. Genes Evol. 2001;211:198-217.

4. Ahmed MU, Maurya AK, Cheng L, Jorge EC, Schubert FR, Maire P, et al. Engrailed controls epaxial-hypaxial muscle innervation and the establishment of vertebrate three-dimensional mobility. Dev Biol. 2017;430: 90-104.

5. Chevallier A, Kieny M, Mauger A. Limb-somite relationship: origin of the limb musculature. J. Embryol. Exp. Morphol. 1977;41:245-58.

6. Christ $\mathrm{B}$, Jacob HJ, Jacob M. Experimental analysis of the origin of the wing musculature in avian embryos. Anat. Embryol. (Berl). 1977;150:171-86.

7. Jacob M, Christ B, Jacob HJ. The migration of myogenic cells from the somites into the leg region of avian embryos - An ultrastructural study. Anat Embryol (Berl). 1979;157:291-309.

8. Noden DM. The embryonic origins of avian cephalic and cervical muscles and associated connective tissues. Am J Anat. 1983;168:257-76.

9. Couly GF, Coltey PM, Le Douarin NM. The triple origin of skull in higher vertebrates: a study in quail-chick chimeras. Development. 1993;117:409-29.

10. Dietrich S. Regulation of hypaxial muscle development. Cell Tissue Res. 1999;296:175-82

11. Buckingham M, Bajard L, Chang T, Daubas P, Hadchouel J, Meilhac S, et al. The formation of skeletal muscle: from somite to limb. J Anat. 2003:202:59-68.

12. Evans DJR, Valasek P, Schmidt C, Patel K. Skeletal muscle translocation in vertebrates. Anat Embryol (Berl). 2006;211:43-50

13. Vasyutina $E$, Birchmeier $C$. The development of migrating muscle precursor cells. Anat. Embryol. (Berl). 2006:211:37-41.

14. Neyt C, Jagla K, Thisse C, Thisse B, Haines L, Currie PD. Evolutionary origins of vertebrate appendivular muscle. Nature. 2000;408:82-5.

15. Alvares LE, Schubert FR, Thorpe C, Mootoosamy RC, Cheng L, Parkyn G, et al. Intrinsic, Hox-dependent cues determine the fate of skeletal muscle precursors. Dev Cell. 2003:5:379-90.

16. Kuratani S. Evolutionary developmental studies of cyclostomes and the origin of the vertebrate neck. Develop Growth Differ. 2008:50:189-94.

17. Bladt F, Riethmacher D, Isenmann S, Aguzzi A, Birchmeier C. Essential role for the c-met receptor in the migration of myogenic precursor cells into the limb bud. Nature. 1995;376:768-71.

18. Tajbakhsh S, Rocancourt D, Cossu G, Buckingham M. Redefining the genetic hierarchies controlling skeletal myogenesis: Pax-3 and Myf-5 act upstream of MyoD. Cell. 1997;89:127-38.

19. Tremblay P, Dietrich S, Mericskay M, Schubert FR, Li Z, Paulin D. A crucial role for Pax3 in the development of the hypaxial musculature and the longrange migration of muscle precursors. Dev Biol. 1998;203:49-61.

20. Schäfer K, Braun T. Early specification of limb muscle precursor cells by the homeobox gene Lbx1h. Nat Genet. 1999;23:213-6.

21. Mankoo BS, Collins NS, Ashby P, Grigorieva E, Pevny LH, Candia A, et al. Mox2 is a component of the genetic hierarchy controlling limb muscle development. Nature. 1999;400:69-73.
22. Brohmann $H$, Jagla $K$, Birchmeier $C$. The role of $L b x 1$ in migration of muscle precursor cells. Development. 2000;127:437-45.

23. Gross MK, Moran-Rivard L, Velasquez T, Nakatsu MN, Jagla K, Goulding M. Lbx1 is required for muscle precursor migration along a lateral pathway into the limb. Development. 2000;127:413-24.

24. Laclef C, Hamard G, Demignon J, Souil E, Houbron C, Maire P. Altered myogenesis in Six1-deficient mice. Development. 2003;130:2239-52.

25. Li X, Oghi KA, Zhang J, Krones A, Bush KT, Glass CK, et al. Eya protein phosphatase activity regulates Six1-Dach-Eya transcriptional effects in mammalian organogenesis. Nature. 2003;426:247-54.

26. Kassar-Duchossoy L, Gayraud-Morel B, Gomès D, Rocancourt D, Buckingham M, Shinin V, et al. Mrf4 determines skeletal muscle identity in Myf5:Myod double-mutant mice. Nature. 2004:431:466-71.

27. Grifone R, Demignon J, Houbron C, Souil E, Niro C, Seller MJ, et al. Six1 and Six4 homeoproteins are required for Pax3 and Mrf expression during myogenesis in the mouse embryo. Development. 2005;132:2235-49.

28. Grifone R, Demignon J, Giordani J, Niro C, Souil E, Bertin F, et al. Eya1 and Eya2 proteins are required for hypaxial somitic myogenesis in the mouse embryo. Dev Biol. 2007:302:602-16.

29. Bryson-Richardson RJ, Currie PD. The genetics of vertebrate myogenesis. Nat Rev Genet. 2008:9:632-46.

30. Buckingham M, Rigby PWJ. Gene regulatory networks and transcriptional mechanisms that control Myogenesis. Dev Cell. 2014;28:225-38.

31. Schmidt C, Bladt F, Goedecke S, Brinkmann V, Zschiesche W, Sharpe M, et al. Scatter factor/hepatocyte growth factor is essential for liver development. Nature. 1995;373:699-702.

32. Uehara Y, Minowa O, Mori C, Shiota K, Kuno J, Noda T, et al. Placental defect and embryonic lethality in mice lacking hepatocyte growth factor/ scatter factor. Nature. 1995;373:702-5.

33. Dietrich $\mathrm{S}$, Abou-rebyeh F, Brohmann H, Bladt F, Sonnenberg-Riethmacher E, Yamaai T, et al. The role of SF/HGF and c-met in the development of skeletal muscle. Development. 1999:1629:1621-9.

34. Maina F, Casagranda F, Audero E, Simeone A, Comoglio PM, Klein R, et al. Uncoupling of Grb2 from the met receptor in vivo reveals complex roles in muscle development. Cell. 1996;87:531-42.

35. Birchmeier C, Birchmeier W, Gherardi E, Vande Woude GF. Met, metastasis, motility and more. Nat Rev Mol Cell Biol. 2003;4:915-25.

36. Prunotto C, Crepaldi T, Forni PE, leraci A, Kelly RG, Tajbakhsh S, et al. Analysis of Mlc-lacZ met mutants highlights the essential function of met for migratory precursors of hypaxial muscles and reveals a role for met in the development of hyoid arch-derived facial muscles. Dev Dyn. 2004;231:582-91.

37. Schnorrer F, Dickson BJ. Muscle building mechanisms of myotube guidance and attachment site selection. Dev Cell. 2004;7:9-20.

38. Andermarcher E, Surani MA, Gherardi E. Co-expression of the HGF/SF and c-met genes during early mouse embryogenesis precedes reciprocal expression in adjacent tissues during organogenesis. Dev Genet. 1996;18:254-66.

39. Daston G, Lamar E, Olivier M, Goulding M. Pax-3 is necessary for migration but not differentiation of limb muscle precursors in the mouse. Development. 1996:122:1017-27.

40. Yang XM, Vogan K, Gros P, Park M. Expression of the met receptor tyrosine kinase in muscle progenitor cells in somites and limbs is absent in splotch mice. Development. 1996;122:2163-71.

41. Birchmeier C, Gherardi E. Developmental roles of HGF/SF and its receptor, the c-met tyrosine kinase. Trends Cell Biol. 1998;8:404-10.

42. Brand-Saberi B, Müller TS, Wilting J, Christ B, Birchmeier C. Scatter factor/ hepatocyte growth factor (SF/HGF) induces emigration of myogenic cells at interlimb level in vivo. Dev Biol. 1996;179:303-8.

43. Heymann S, Koudrova M, Arnold HH, Köster M, Braun T. Regulation and function of SF/HGF during migration of limb muscle precursor cells in chicken. Dev Biol. 1996:180:566-78.

44. Mennerich D, Schäfer K, Braun T. Pax-3 is necessary but not sufficient for $1 b x 1$ expression in myogenic precursor cells of the limb. Mech Dev. 1998;73:147-58

45. Haines L, Neyt C, Gautier P, Keenan DG, Bryson-Richardson RJ, Hollway GE, et al. Met and Hgf signaling controls hypaxial muscle and lateral line development in the zebrafish. Development. 2004:131:4857-69.

46. Epstein JA, Shapiro DN, Cheng J, Lam PY, Maas RL. Pax3 modulates expression of the c-met receptor during limb muscle development. Proc Natl Acad Sci U S A. 1996;93:4213-8. 
47. Scaal M, Bonafede A, Dathe V, Sachs M, Cann G, Christ B, et al. SF/HGF is a mediator between limb patterning and muscle development. Development. 1999;126:4885-93

48. Mic FA, Duester G. Patterning of forelimb bud myogenic precursor cells requires retinoic acid signaling initiated by Raldh2. Dev Biol. 2003;264: $191-201$.

49. Bonafede A, Köhler T, Rodriguez-Niedenführ M, Brand-Saberi B. BMPs restrict the position of premuscle masses in the limb buds by influencing Tcf4 expression. Dev Biol. 2006;299:330-44.

50. Latimer AJ, Jessen JR. Hgf/C-met expression and functional analysis during zebrafish embryogenesis. Dev Dyn. 2008;237:3904-15.

51. Adachi N, Pascual-Anaya J, Hirai T, Higuchi S, Kuratani S. Development of hypobranchial muscles with special reference to the evolution of the vertebrate neck. Zool. Lett. 2018, Accepted.

52. Theiler K. The house mouse. Atlas of embryonic development. New York: Springer-Verlag Berlin Heidelberg; 1989.

53. Hamburger $\mathrm{V}$, Hamilton HL. A series of normal stages in the development of the chick embryo. J Morphol. 1951;88:49-92.

54. Ballard WW, Mellinger J, Lechenault $H$. A series of normal stages for development of Scyliorhinus canicula, the lesser spotted dogfish (Chondrichthyes: Scyliorhinidae). J Exp Zool. 1993;267:318-36.

55. Tahara Y. Normal stages of development in the lamprey, Lampetra reissneri (Dybowski). Zool Sci. 1988:5:109-18

56. Adachi N, Takechi M, Hirai T, Kuratani S. Development of the head and trunk mesoderm in the dogfish, Scyliorhinus torazame: II. Comparison of gene expression between the head mesoderm and somites with reference to the origin of the vertebrate head. Evol. Dev. 2012;14:257-76.

57. Katoh K, Standley DM. MAFFT multiple sequence alignment software version 7: improvements in performance and usability. Mol Biol Evol. 2013;30:772-80

58. Capella-Gutierrez S, Silla-Martinez JM, Gabaldon T. trimAl: a tool for automated alignment trimming in large-scale phylogenetic analyses. Bioinformatics. 2009;25:1972-3.

59. Ronquist F, Teslenko M, van der Mark P, Ayres DL, Darling A, Hohna S, et al. MrBayes 3.2: efficient Bayesian phylogenetic inference and model choice across a large model space. Syst Biol. 2012;61:539-42.

60. Adachi N, Robinson M, Goolsbee A, Shubin NH. Regulatory evolution of Tbx5 and the origin of paired appendages. Proc Natl Acad Sci U S A. 2016;113:10115-20.

61. Houzelstein D, Auda-Boucher G, Chéraud Y, Rouaud T, Blanc I, Tajbakhsh S, et al. The homeobox gene Msx1 is expressed in a subset of somites, and in muscle progenitor cells migrating into the forelimb. Development. 1999;126:2689-701.

62. Myokai F, Washio N, Asahara Y, Yamaai T, Tanda N, Ishikawa T, et al. Expression of the hepatocyte growth factor gene during chick limb development. Dev Dyn. 1995;202:80-90.

63. Théry C, Sharpe MJ, Batley SJ, Stern CD, Gherardi E. Expression of HGF/SF, HGF1/MSP, and c-met suggests new functions during early chick development. Dev Genet. 1995;17:90-101.

64. Mackenzie S, Walsh FS, Graham A. Migration of hypoglossal myoblast precursors. Dev Dyn. 1998;213:349-58.

65. Theis S, Patel K, Valasek P, Otto A, Pu Q, Harel I, et al. The occipital lateral plate mesoderm is a novel source for vertebrate neck musculature. Development. 2010;137:2961-71.

66. Balfour MF. A monograph on the development of elasmobranch fishes. London: MacMillan and co; 1878.

67. Adachi N, Kuratani S. Development of head and trunk mesoderm in the dogfish, Scyliorhinus torazame: I. Embryology and morphology of the head cavities and related structures. Evol Dev. 2012;14:234-56.

68. Pascual-Anaya J, Sato I, Sugahara F, Higuchi S, Paps J, Yandong R, et al. Hagfish and lamprey Hox genes reveal conservation of temporal colinearity in vertebrates. Nat Ecol Evo 2018;2():859-866.

69. Lin CY, Yung RF, Lee HC, Chen WT, Chen YH, Tsai HJ. Myogenic regulatory factors Myf5 and Myod function distinctly during craniofacial myogenesis of zebrafish. Dev Biol. 2006;299:594-608.

70. Elsen GE, Choi LY, Prince VE, Ho RK. The autism susceptibility gene met regulates zebrafish cerebellar development and facial motor neuron migration. Dev Biol. 2009;335:78-92.

71. Anderson RM, Delous M, Bosch JA, Ye L, Robertson MA, Hesselson D, et al. Hepatocyte growth factor signaling in Intrapancreatic ductal cells drives pancreatic morphogenesis. PLoS Genet. 2013;9:1-10.
72. Trusolino L, Bertotti A, Comoglio PM. MET signalling: principles and functions in development, organ regeneration and cancer. Nat. Rev. Mol. Cell Biol. 2010;11:834-48.

73. Lours-Calet C, Alvares LE, El-Hanfy AS, Gandesha S, Walters EH, Sobreira DR, et al. Evolutionarily conserved morphogenetic movements at the vertebrate head-trunk interface coordinate the transport and assembly of hypopharyngeal structures. Dev Biol. 2014;390:231-46.

74. Cole NJ, Hall TE, Don EK, Berger S, Boisvert CA, Neyt C, et al. Development and evolution of the muscles of the pelvic fin. PLoS Biol. 2011;9:16-8.

75. Okamoto E, Kusakabe R, Kuraku S, Hyodo S, Robert-Moreno A, Onimaru K, et al. Migratory appendicular muscles precursor cells in the common ancestor to all vertebrates. Nat. Ecol. Evol. 2017;1:1731-6.

76. Bothe I, Ahmed MU, Winterbottom FL, Von Scheven G, Dietrich S. Extrinsic versus intrinsic cues in avian paraxial mesoderm patterning and differentiation. Dev Dyn. 2007;236:2397-409.

77. True JR, Haag ES. Developmental system drift and flexibility in evolutionary trajectories. Evol. Dev. 2001;3:109-19.

78. Swartz ME, Eberhart J, Pasquale EB, Krull CE. EphA4/ephrin-A5 interactions in muscle precursor cell migration in the avian forelimb. Development. 2001;128:4669-80.

79. Vasyutina E, Stebler J, Brand-Saberi B, Schulz S, Raz E, Birchmeier C. CXCR4 and Gab1 cooperate to control the development of migrating muscle progenitor cells. Genes Dev. 2005;19:2187-98.

80. Rehimi R, Khalida N, Yusuf F, Morosan-Puopolo G, Brand-Saberi B. A nove role of CXCR4 and SDF-1 during migration of cloacal muscle precursors. Dev Dyn. 2010;239:1622-31.

81. Masyuk M, Abduelmula A, Morosan-Puopolo G, Ödemis V, Rehimi R, Khalida $\mathrm{N}$, et al. Retrograde migration of pectoral girdle muscle precursors depends on CXCR4/SDF-1 signaling. Histochem Cell Biol. 2014;142:473-88.

\section{Ready to submit your research? Choose BMC and benefit from:}

- fast, convenient online submission

- thorough peer review by experienced researchers in your field

- rapid publication on acceptance

- support for research data, including large and complex data types

- gold Open Access which fosters wider collaboration and increased citations

- maximum visibility for your research: over $100 \mathrm{M}$ website views per year

At BMC, research is always in progress.

Learn more biomedcentral.com/submissions 